\title{
Surface Integrity Analysis when Milling Ultrafine-grained Steels
}

\author{
Alessandro Roger Rodrigues ${ }^{\mathrm{a}}$, Oscar Balancin ${ }^{\mathrm{b}}$, Juno Gallego ${ }^{\mathrm{c}}$, \\ Cleiton Lazaro Fazolo de Assis ${ }^{a}$, Hidekasu Matsumoto ${ }^{c}$,Fernando Brandão de Oliveira ${ }^{c}$, \\ Suzana Regina da Silva Moreirac, Otavio Villar da Silva Neto ${ }^{\mathrm{d}}$ \\ ${ }^{a}$ Mechanical Engineering Department, Engineering School of São Carlos, \\ University of São Paulo - USP, Trabalhador São-Carlense Avenue, 400, \\ CEP 13566-590, São Carlos, SP, Brazil \\ ${ }^{\mathrm{b}}$ Materials Engineering Department, Federal University of São Carlos - UFSCar, \\ Washington Luís, Km 235, CEP 13565-905, São Carlos, SP, Brazil \\ 'Mechanical Engineering Department, Engineering Faculty of Ilha Solteira, \\ Univ Estadual Paulista - UNESP, Brasil Centro Avenue, 56, \\ CEP 15385-000, Ilha Solteira, SP, Brazil \\ ${ }^{d}$ Paulista University - UNIP, Presidente Juscelino Kubitschek de Oliveira Avenue, \\ CEP 15091-450, São José do Rio Preto, SP, Brazil
}

Received: August 10, 2011; Revised: October 7, 2011

This paper quantifies the effects of milling conditions on surface integrity of ultrafine-grained steels. Cutting speed, feed rate and depth of cut were related to microhardness and microstructure of the workpiece beneath machined surface. Low-carbon alloyed steel with $10.8 \mu \mathrm{m}$ (as-received) and $1.7 \mu \mathrm{m}$ (ultrafine) grain sizes were end milled using the down-milling and dry condition in a CNC machining center. The results show ultrafine-grained workpiece preserves its surface integrity against cutting parameters more than the as-received material. Cutting speed increases the microhardness while depth of cut deepens the hardened layer of the as-received material. Also, deformations of microstructure following feed rate direction were observed in workpiece subsurface.

Keywords: milling, surface integrity, microstructure, microhardness, ultrafine-grained steel

\section{Introduction}

Surface integrity is defined as metallurgical modifications in the surface and surface layer of a workpiece caused by manufacturing processes ${ }^{1}$. Nowadays the surface integrity is strongly discussed given the requirements for mechanical components such as performance, functionality and high reliability. Thus, the surface integrity can play an important role when using the machined parts for instance in mobility industries ${ }^{2}$.

Low-carbon steels with ultrafine grains $(<5 \mu \mathrm{m})$ have been significantly studied due to the gain in mechanical properties aiming at applications in high performance components ${ }^{3}$. Several processing routes have been formulated for this purpose which are supported by phenamena like subgrain/grain formation by severe deformations at room temperature, dynamic transformation of phase induced by deformation, continuous dynamic recrystallization of ferrite at hot work. There are promising perspectives for application of ultrafine-grained steels, not only in sheets, but also in parts with greater dimensions, such as shafts (steering, propulsion, cardan), wheels, impact bars, shock absorbers, universal joints and toothed racks. Thus, the tendency will be to machine these components adopting

*e-mail: roger@sc.usp.br techniques so-called high performance cutting, high-speed machining, micromachining or high precision machining.

High-Speed Machining (HSM) is industrially defined when cutting speed is elevated and feed per tooth and depth of cut are diminished normally aiming at finishing operations ${ }^{4}$. This technology can be very efficiently applied in aeronautical, automotive and molds/dies industries to produce dimensionally precise and free-form geometry parts ${ }^{5,6}$. But, even if these manufacturing processes technologically advanced are not properly controlled, such as feed rate oscillations, they may affect the costs, lead-time and quality of products ${ }^{6}$. Besides, some advantages of HSM such as decrease of temperatures and forces can be decisive for workpiece surface integrity. Despite these supposed benefits, many scientific results are still contradictory mainly about workpiece surface integrity.

Saii ${ }^{7}$ studied the microhardness behavior due to cutting speed variation and concluded that microhardness in milled surfaces increased with cutting speed. In contrast, $\mathrm{Silva}^{8}$ verified microhardness was not affected by milling of the AISI H13 steel when cutting conditions were varied. Kannan and Kishawy ${ }^{9}$ declare particle volume fraction and average size profoundly affect the extent of plastic deformation of the material, but Rodrigues et al. ${ }^{10}$ even changing the 
workpiece volume fraction did not find plastic deformations near machined surface.

The objective of this research was to quantify the influence of the cutting speed, feed per tooth and depth of cut, mainly at high-speed machining, on the microhardness and microstructure of low-carbon alloyed steel with ultrafine grains still not used in machining.

\section{Materials and Methods}

The milling tests were carried out in a CNC machining center with $11 \mathrm{~kW}$ power and 10,000 rpm maximum spindle rotation. A $25 \mathrm{~mm}$ diameter cutter tool with two cemented carbide inserts coated with $\mathrm{Al}_{2} \mathrm{O}_{3}$ layer (code R390-11 T3 08M-PM 4030 and grade ISO P25) was employed for the endmill operation adopting down-milling condition.

Rolled low-carbon alloyed steel with $10 \times 24$ x 100 mm was used for milling tests. The main chemical elements are $0.15 \% \mathrm{C}, 1.49 \% \mathrm{Mn}, 0.276 \% \mathrm{Cr}, 0.008 \% \mathrm{Ni}, 0.048 \% \mathrm{Nb}$, $0.044 \% \mathrm{~V}$ and $0.016 \% \mathrm{Ti}$. The as-received $(198 \pm 2.6 \mathrm{HV})$ and ultrafine-grained $(322 \pm 7.3 \mathrm{HV})$ materials present ferritic grain size of $10.8 \pm 3.8 \mu \mathrm{m}$ and $1.7 \pm 0.32 \mu \mathrm{m}$, respectively (ASTM E 112-96 standard). Figure 1 illustrates the microstructure morphology.

Figure 1a shows a microstructure composed by ferrite and pearlite in clear and dark color, respectively, with grain contours well-defined even in ferrite-ferrite interface. The ferrite morphology is polygonal with long and narrow pearlitic structures aligned according to the rolling direction. Figure $1 \mathrm{~b}$ presents polygonal ferritic ultrafine grains with some probable occurrences of bainite and martensite.
To obtain ultrafine-grained steels, the as-received materials were submitted to microstructural conditioning and thermo-mechanical processing. The first stage consisted in water quenching aiming at obtaining fine martensitic microstructure. The second one based on heating and passes of rolling with reheating in furnace among passes. Finally, the workpieces were heated at intercritical temperature with subsequent water cooling. Figure 2 shows the specimens from as-received and ultrafine-grained steel used for machining tests.

For machining tests, the cutting parameters adopted were 100 and $600 \mathrm{~m} / \mathrm{min}$ cutting speed $\left(\mathrm{v}_{\mathrm{c}}\right), 0.5$ and $3.0 \mathrm{~mm}$ depth of cut $\left(\mathrm{a}_{\mathrm{p}}\right)$ and 0.05 and $0.2 \mathrm{~mm} / \mathrm{z}$ feed per tooth $\left(\mathrm{f}_{\mathrm{z}}\right)$. The machining conditions assumed as HSM were extracted by combining parameters with maximum $\mathrm{v}_{\mathrm{c}}$ and minimum $\mathrm{a}_{\mathrm{p}}$ and $\mathrm{f}_{\mathrm{z}}$. All machining tests were carried out twice in dry condition with $2 \mathrm{~mm}$ width of cut $\left(\mathrm{a}_{\mathrm{e}}\right)$ and linear tool path in the $\mathrm{x}$-axis direction only. The cutting parameters were based on ranges indicated in Tönshoff et al. ${ }^{4}$ and Chevrier et al. ${ }^{11}$. A new cutting edge was used for each test to assure the equal initial conditions since tool wear should not interfere on the workpiece surface integrity. Table 1 summarizes all milling conditions applied in tests.

Statistical evaluation considering Analysis of Variance (ANOVA) with $2^{3}$ factorial design, statistical significance $\alpha=5 \%$, and two replicates was employed adopting three factors and two levels such as showed in Table 1. Additionally, the paired test-t (Student's distribution) was applied for microhardness measurements (workpiece bulk and milled border) by considering $n=4$ (samples

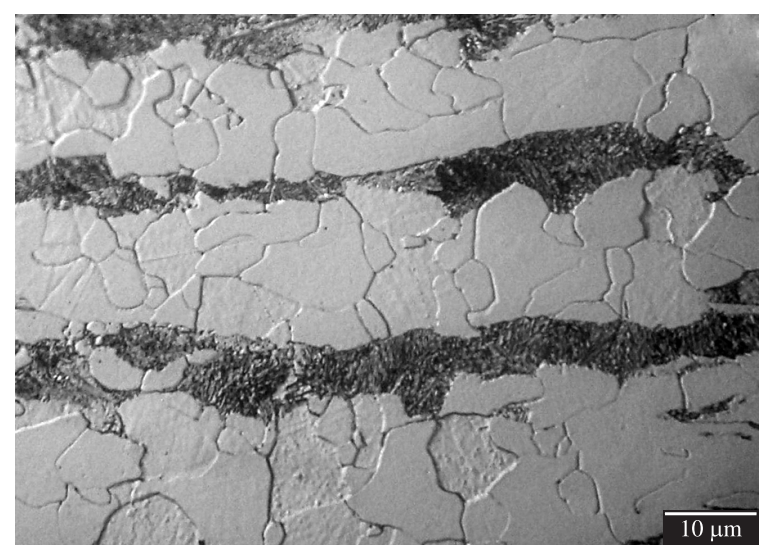

(a)

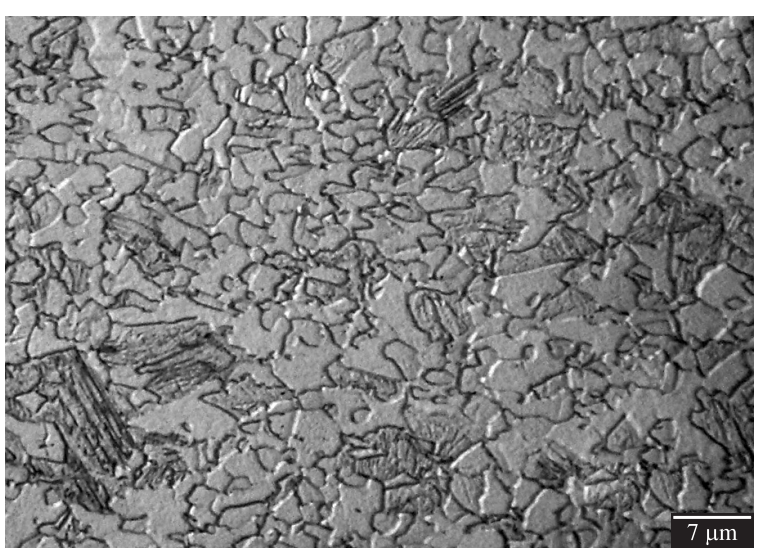

(b)

Figure 1. a) Rolled as-received material, and b) ultrafine-grained steel.

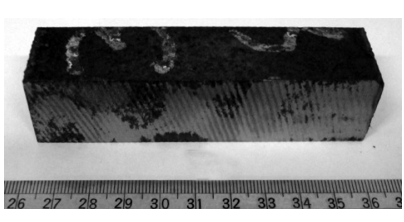

(a)

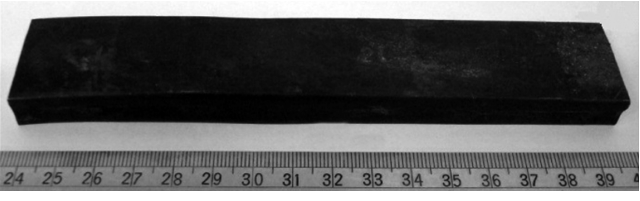

(b)

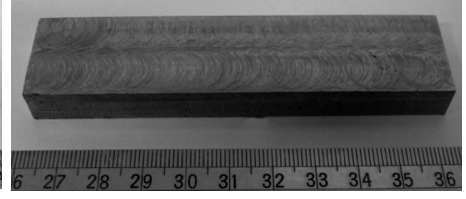

(c)

Figure 2. a) As-received material, b) ultrafine grain (rolled), and c) pre-machined specimen for final milling tests independent on the bulk microstructure. 
Table 1. Milling conditions used in the machining tests.

\begin{tabular}{|c|c|c|c|c|c|c|c|c|c|}
\hline \multirow[t]{2}{*}{ Factors } & \multirow[t]{2}{*}{ Levels } & \multicolumn{8}{|c|}{ Milling conditions } \\
\hline & & C1 & $\mathrm{C} 2$ & C3 & $\mathrm{C4}$ & $\mathrm{C5}^{*}$ & C6 & C7 & C8 \\
\hline $\mathrm{v}_{\mathrm{c}}[\mathrm{m} / \mathrm{min}]$ & $100 / 600$ & 100 & 100 & 100 & 100 & 600 & 600 & 600 & 600 \\
\hline $\mathrm{a}_{\mathrm{p}}[\mathrm{mm}]$ & $0.5 / 3.0$ & 0.5 & 0.5 & 3.0 & 3.0 & 0.5 & 0.5 & 3.0 & 3.0 \\
\hline $\mathrm{f}_{\mathrm{z}}[\mathrm{mm} /$ tooth $]$ & $0.05 / 0.20$ & 0.05 & 0.20 & 0.05 & 0.20 & 0.05 & 0.20 & 0.05 & 0.20 \\
\hline
\end{tabular}

*High-speed machining condition.

size), $n-1=3$ (degrees of freedom) and $\alpha=5 \%$ (statistical significance).

For microstructural characterization and microhardness measurements after machining, the milled workpieces were cross-sectionally sawed, hot cupped in bakelite and sanded with 120, 220, 400, 600 and 1000 sandpapers. After, the specimens with $8 \times 10 \times 10 \mathrm{~mm}$ were polished with aluminum oxide $(1$ and $0.3 \mu \mathrm{m})$, diamond past $(0.25 \mu \mathrm{m})$ and etched using reagent Nital $2 \%$ by 5 seconds. The microstructure images were obtained by the Scanning Electron Microscope (SEM).

The microhardness profile beneath milled surface was measured only in ferrite grains using an ultra microhardness tester considering the load-unload method, Vickers indentation (20 and $100 \mathrm{mN}$ for as-received and ultrafine grain material, respectively) and ISO 14577-1 standard. The depth evaluated reached $145 \mu \mathrm{m}$ and each indentation presented four replications.

To measure the microhardness closest to the milled workpiece border, two pairs of specimens from different machining conditions were cupped in the same sample. Thus, two replicates from a given milling condition were positioned in front of other ones from distinct milling condition. This strategy allowed minimizing the bulging effect and obtaining reliable indentations about $5 \mu \mathrm{m}$ from the machined workpiece border. In addition, interface junction between workpiece pairs was quite plan due to the milling process, facilitating the contact and minimizing the bulging during metallographic preparation. Figure 3 presents this proposed mounting and examples of uniform indentations are shown in Figure 4.

\section{Results and Discussion}

Figure 5 presents micrographic images near machined surface. The photos were chosen for groups of machining conditions where feed per tooth was varied intentionally since this parameter did not influence on workpiece microstructure significantly (proved by ANOVA with $p$-value $=0.860>\alpha=0.05$ ). Thus, Figure 5a reveals a milled surface of the as-received material unaffected by cutting parameters given the absence of deformation lines of the border grains toward feed rate.

A machined surface with sensitive deformation of grains near milled border may be observed in Figure 5b. This effect probably is associated to the depth of cut rise. Figure $5 \mathrm{c}$ shows the region next to the surface machined at HSM where grain deformations were more significant due to the increase of shear rate determined by high cutting speed. Finally, Figure $5 \mathrm{~d}$ shows that the global influence between the cutting speed and depth of cut caused intense deformation of the

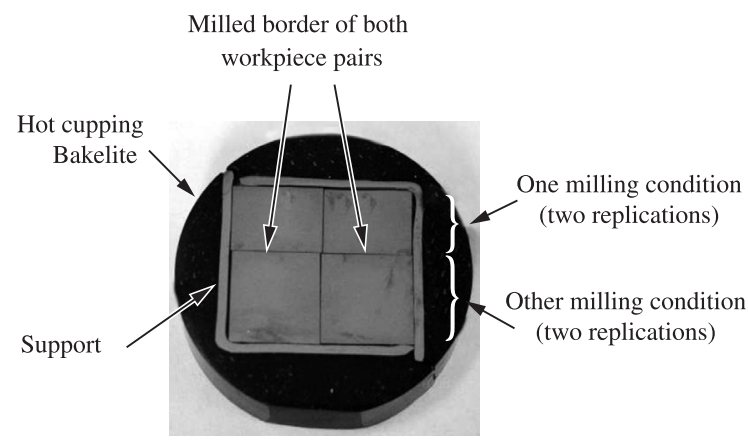

Figure 3. Strategy for cupping of the specimens used for microhardness measurements and microstructure analyses.

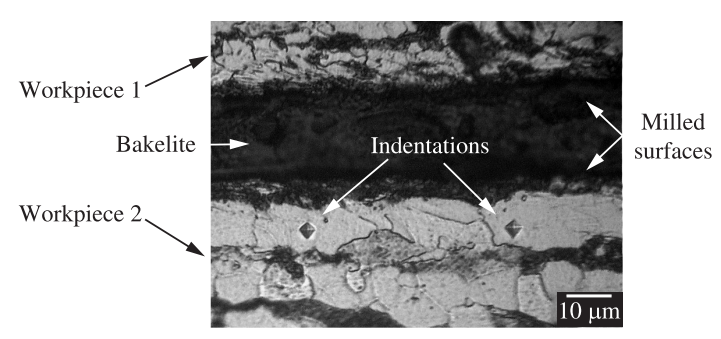

Figure 4. Example of indentations at $5 \mu \mathrm{m}$ next to the milled workpiece border (as-received material).

grains near milled border. Figure 5e and 5f (high cutting speed) present the microstructure close to milled surface of the ultrafine-grained workpieces. It was possible to note there is not plastic deformation for any combination of milling parameters. The higher hardness reached by grain refinement imposed strain resistance and preserved the surface integrity of machined surface. The decrease of grain size elevates the grain contours area which act like barriers, hindering dislocations movement and increasing the strain resistance of material.

This microhardness behavior was not verified by $\mathrm{Pu}$ et al. ${ }^{12}$ when machining biomaterial AZ31Mg alloy. Similarly to the as-received material, the authors found deformed grains toward the feed rate up to $7 \mu \mathrm{m}$ beneath machined surface. When the tool cutting edge radius was increased from 30 to $70 \mu \mathrm{m}$, the deformed microstructure layer reached $15 \mu \mathrm{m}$ thickness including microhardness rise by about $60 \%$.

Figure 6 shows the microhardness measurements beneath machined surface. The curves represent all cutting conditions and divide the whole results into well-defined behaviors for each workpiece material. 


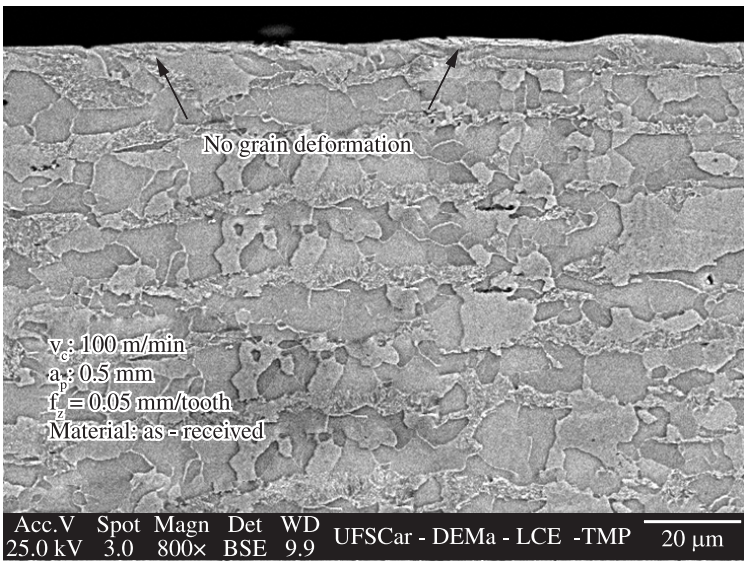

(a)

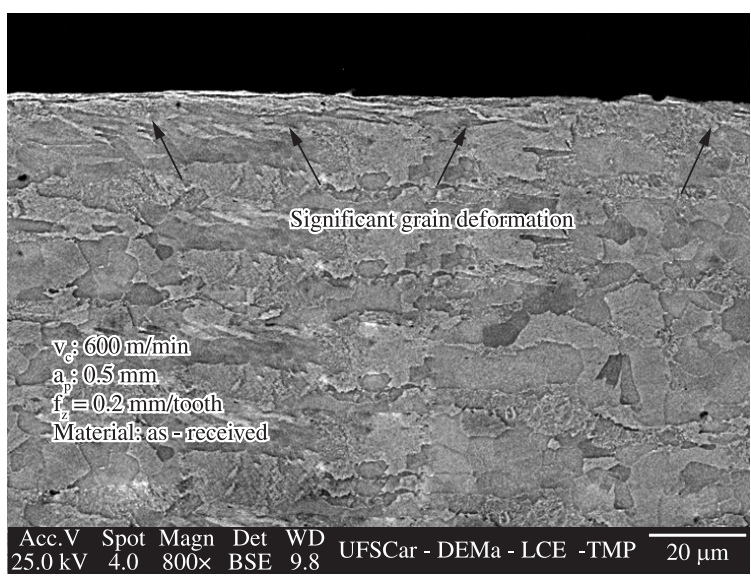

(c)

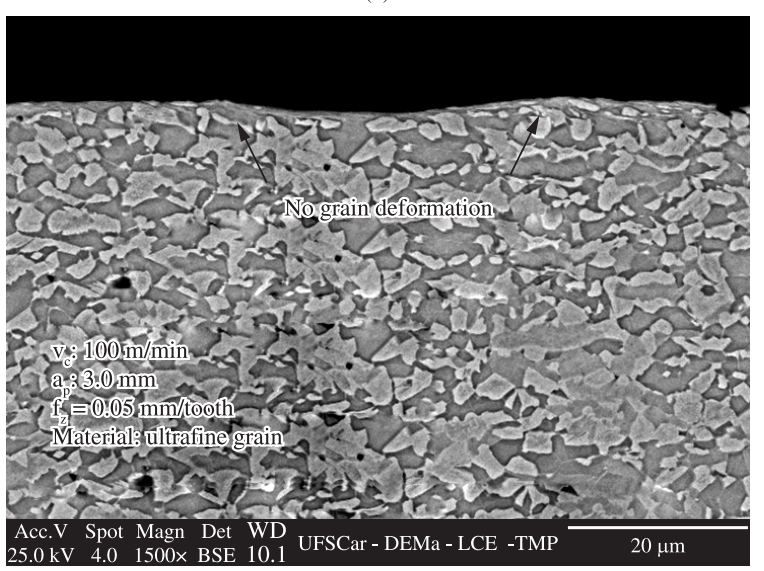

(e)

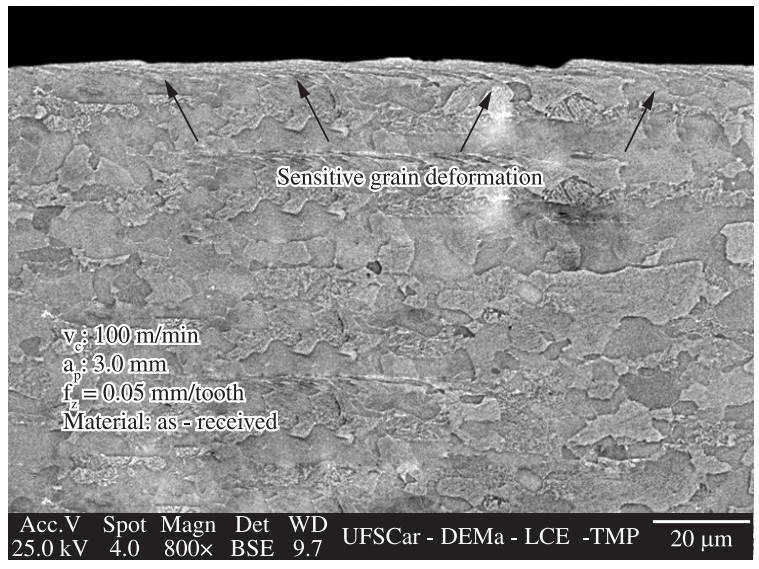

(b)

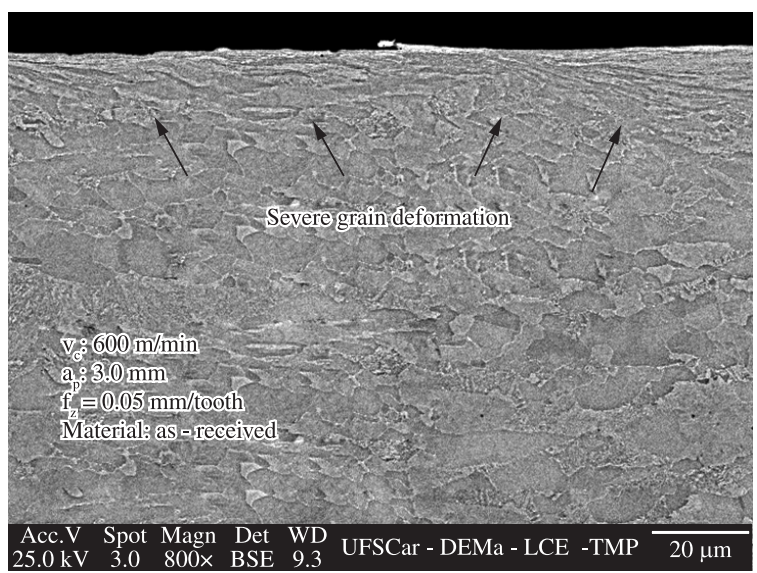

(d)

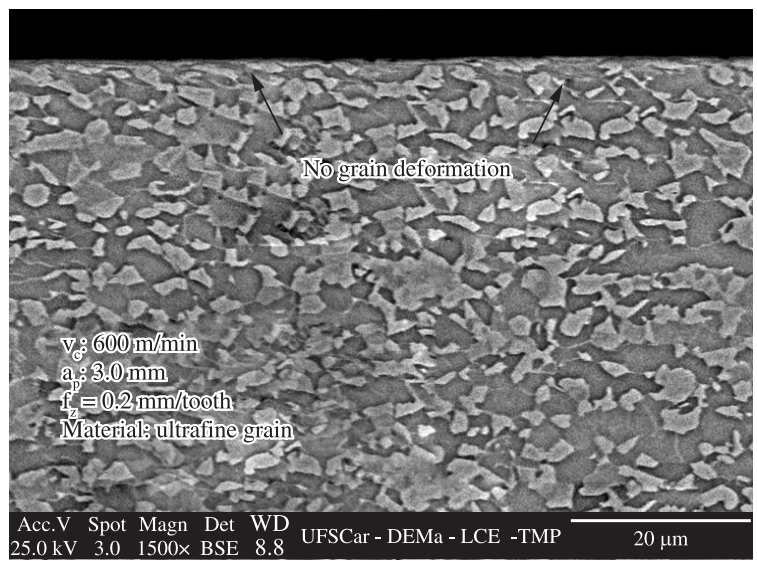

(f)

Figure 5. Microstructure of workpieces beneath milled surfaces.

The profiles evidence that microhardness increased next to machined surface for almost all workpieces and this effect was more or less pronounced depending on cutting parameters. It was certified by ANOVA that the feed per tooth did not influence significantly neither microhardness rise nor extension of hardened layer ( $p$-value $=0.860$ ). On the other hand, for as-received material the cutting speed and depth of cut affected decisively the microhardness rise $(\mathrm{p}$-value $=0.032)$ and hardened layer $(\mathrm{p}$-value $\approx 0)$, respectively (Figure 6a and 6b). This behavior demonstrates to be compatible to the microstructure modifications related to grain deformations i.e. cutting speed hardened workpiece through higher shear rate while depth of cut extended the affected layer by means of higher shear level or removed volume.

The microhardness profile for the ultrafine-grained steels did not follow a pattern similar to the as-received material. Three milling conditions varied the microhardness 


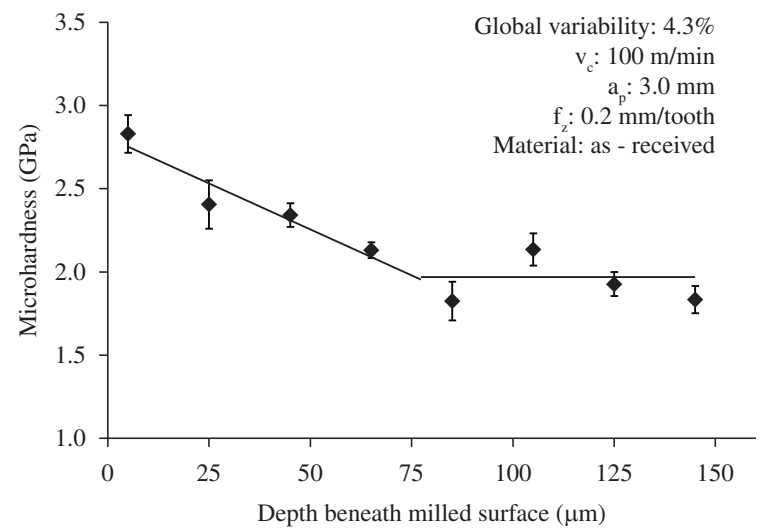

(a)

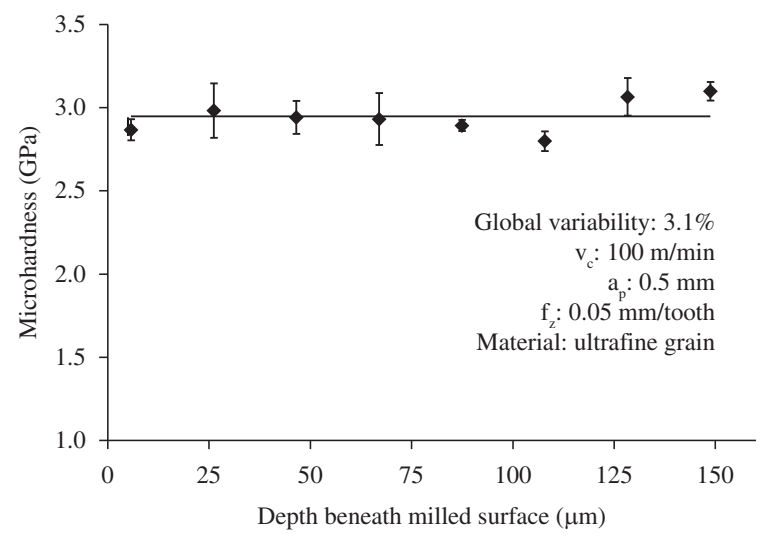

(c)

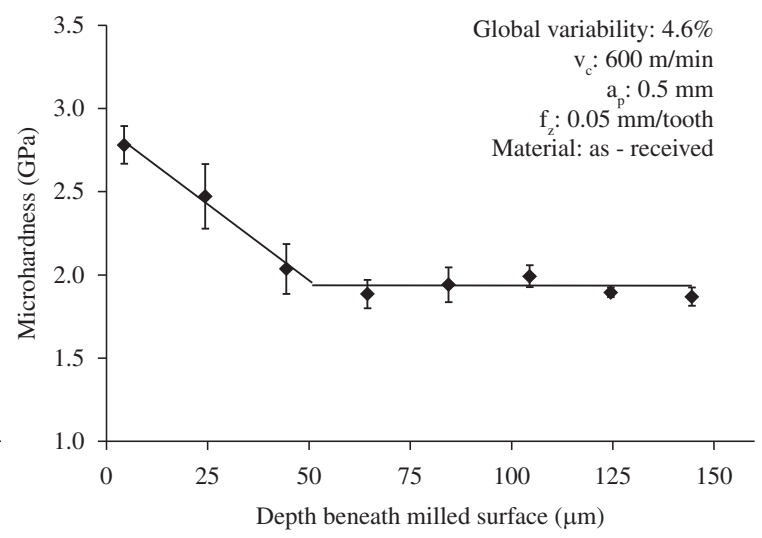

(b)

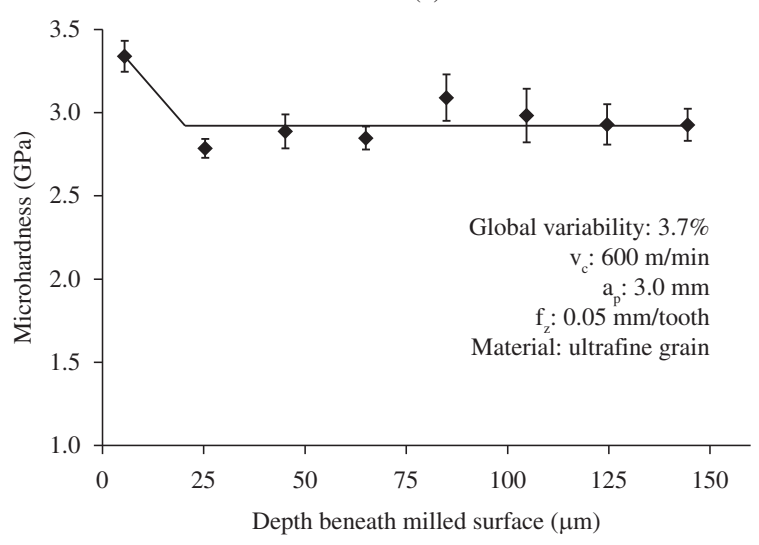

(d)

Figure 6. Microhardness profiles in the subsurface of the workpieces

strongly (C4, C5 and C6), two of them affected slightly (C2 and $\mathrm{C7}$ ) and other three ones presented null influence (C1, $\mathrm{C} 3$ and $\mathrm{C} 8$ ). So, the cutting parameters did not influence statistically the microhardness given the p-value greater than the statistical significance, except for cutting speed $(\mathrm{p}$-value $=0.044)$. Figure $6 \mathrm{c}$ shows a milling condition where all cutting parameters were smallest and Figure 6d represents the machining condition with high cutting speed.

By applying the paired test-t as earlier mentioned, it was possible to prove that the microhardness measurements of the material bulk (as-received and ultrafine grain) are different statistically since $p$-value calculated $\left(t_{3: 0.95}=-6.198\right)$ is lesser than the threshold tabulated for the statistical significance $\left(\mathrm{t}_{3: 0.95}=3.182\right)$. In addition, the microhardness was equivalent to the macrohardness presented in section 2. Similarly, the comparison among border microhardness data from asreceived and ultrafine-grained materials milled under all cutting conditions was different statistically because $\mathrm{p}$-value $\mathrm{t}_{3: 0.05}=-2.961<3.182$. Despite the border microhardness measurements for ultrafine-grained steel were greater than those for as-received material, the relative increasing by considering the bulk microhardness was lesser.

All findings abovementioned indicate that ultrafinegrained steel tends to preserve its surface integrity because for most of cutting conditions little or no microhardness variation took place. Even at high cutting speed the material had a small increase of microhardness and a shallow affected layer, proving that just cutting speed influences on microhardness. Thus, these results are in accordance with the microstructural behavior since the elevation of grain contours area given the grain refinement increased the resistance not only to hardening but also to plastic deformation of material.

Jawahir et al. ${ }^{13}$ did not also measure microhardness variations when milling AISI 52100 steel (100Cr6), but some increase should exist near machined surface because compressive residual stress was quantified at depths of up to $250 \mu \mathrm{m}$. According to the authors, the main reason for this incompatibility refers to the lower sensitivity of the hardness measurer since induced plastic deformation affects the results of X-ray diffraction more significantly. In addition, the workpiece material does not seem to be prone to strainhardening in its hardened and annealed state.

\section{Conclusions}

- The subsurface microhardness of workpiece after machining may present different behaviors depending on grain size. For larger grain sizes, cutting speed increases the microhardness, depth of cut extends the hardened layer and feed per tooth does not play a significant role. For smaller grain sizes just cutting speed acts on depth of hardened layer; 
- The microstructure near machined surface is more sensitive for workpieces with larger grain sizes than for smaller ones. Cutting speed and depth of cut are parameters more influent on grain deformation at the border of workpiece;

- Ductile low-carbon steels are also susceptible to surface integrity alterations, depending on cutting conditions;

- The grain size of workpiece plays a central role in minimizing interferences on workpiece surface integrity due to the machining process;

\section{References}

1. Field M, Kahles JF and Koster WP. Surface finish and surface integrity. In: American Society for Metals. ASM Metals Handbook: Machining. Ohio: ASM; 1999. v. 16, p. 43-84.

2. Ezugwu EO and Tang SH. Surface abuse when machining cast iron (G-17) and nickel-base superalloy (Inconel 718) with ceramic tools. Journal of Materials Processing Technology. 1995; 55:63-69. http://dx.doi.org/10.1016/09240136(95)01786-0

3. Gao M, Zeng X, Hu Q and Yan J. Laser-TIG welding of ultra-fine grained steel. Journal of Materials Processing Technology. 2009; 209(2):785-791. http://dx.doi.org/10.1016/j. jmatprotec.2008.02.062

4. Tönshoff HK, Friemuth T, Andrae P and Amor RB. High-speed or high-performance cutting - a comparison of new machining technologies. Production Engineering. 2001; 8(1):5-8.

5. Brandão LC, Coelho RT and Rodrigues AR. Experimental and theoretical study of workpiece temperature when end milling hardened steels using (TiAl)N-coated and PcBN-tipped tools. Journal of Material Processing Technology. 2008; 99:234-244.

6. Souza AF, Souza AF, Roger AR, Rigatti AMY and Ribeiro A AL. Mechanistic approach to predict real machining time for milling free-form geometries applying high feed rate. International Journal of Advanced Manufacturing Technology. 2010; 46(9-12):1103-1111. http://dx.doi.org/10.1007/s00170009-2183-8

7. Saï WB, Sai WB, Salah NB and Lebrun JL. Influence of machining by finishing milling on surface characteristics. International Journal of Machine Tools and Manufacture. 2000; 41(3):443-450.
- Machining with higher cutting speeds and depths of cut should be applied with caution, especially in parts with grain size non-refined.

\section{Acknowledgements}

The authors are grateful to the São Paulo Research Foundation (FAPESP), Education Ministry Foundation (CAPES) and National Council for Scientific and Technological Development (CNPq) for financial support.

8. Silva MM, Abrão AM, Coelho RT and Campos WRC. Integridade superficial de peças fresadas e retificadas. Revista Máquinas e Metais. 2006; 42(481):136-151.

9. Kannan S and Kishawy HA. Surface characteristics of machined aluminium metal matrix composites. International Journal of Machine Tools and Manufacture. 2006; 46:2017-2025. http:// dx.doi.org/10.1016/j.ijmachtools.2006.01.003

10. Rodrigues AR, Matsumoto H, Yamakami WJ, Paulo RGR and Assis CLF. Effects of milling condition on the surface integrity of hot forged steel. Journal of the Brazilian Society of Mechanical Sciences and Engineering. 2010; 32(1):37-43. http://dx.doi.org/10.1590/S1678-58782010000100006

11. Chevrier A, Tidu A, Bolle B, Cezard P and Tinnes JP. Investigation of surface integrity in high speed end milling of a low alloyed steel. International Journal of Machine Tools and Manufacture. 2003; 43(11):1135-1142. http://dx.doi. org/10.1016/S0890-6955(03)00122-6

12. Pu Z, Dillon Junior OW, Jawahir IS and Puleo DA. Microstructural changes of AZ31 magnesium alloys induced by cryogenic machining and its influence on corrosion resistance in simulated body fluid for biomedical applications. In: Proceedings of the International Manufacturing Science and Engineering Conference; 2010; Erie, USA. Pennsylvania: ASME; 2010. p. 271-277.

13. Jawahir IS, Brinksmeier E, M'Saoubi R, Aspinwall DK, Outeiro JC, Meyer D et al. Surface integrity in material removal processes: recent advances. CIRP Annals - Manufacturing Technology. 2011; 60(2):603-626. http://dx.doi.org/10.1016/j. cirp.2011.05.002 